\title{
Intramedullary Spinal Cord and Brain Metastases from Thyroid Carcinoma Detected 11 Years after Initial Diagnosis - Case Report-
}

\author{
Yutaka HonMA, Kenya KAWAKITA, and Seigo NAGAO
}

Department of Neurological Surgery, Kagawa Medical University, Kagawa

\begin{abstract}
A 60-year-old male presented with a rare intramedullary spinal cord metastasis from thyroid carcinoma manifesting as rapidly worsening motor and sphincter disturbances. The primary tumor had been treated 11 years previously. Magnetic resonance imaging clearly revealed the hemorrhagic tumor localized in the thoracic spinal cord and an associated, asymptomatic metastasis in the cerebellum. The hypervascular tumors were totally removed. The histological diagnosis was papillary adenocarcinoma. $\mathrm{He}$ has been stable for 2 years postoperatively. Surgical resection of intramedullary metastasis should be considered in patients with less malignant tumors such as thyroid carcinoma, especially when accompanied by progressive compression myelopathy.
\end{abstract}

Key words: spinal metastasis, thyroid carcinoma, intramedullary spinal cord tumor, magnetic resonance imaging

\section{Introduction}

Intramedullary spinal cord metastases of nonneurogenic origin are uncommon in contrast to extradural spinal metastases, and comprise from $0.9 \%$ to $8.5 \%$ of all metastases to the central nervous system. ${ }^{1,3,11,14)}$ The incidence at autopsy ranges from $0.9 \%$ to $2.1 \%$ in cancer patients. Most cases are confirmed at autopsy ${ }^{20)}$ or diagnosed in the advanced stage, so surgical removal is very seldom indicated. ${ }^{5}$ However, the incidence is likely to increase with the improved survival of cancer patients. ${ }^{5}$ More accurate diagnostic procedures such as high resolution magnetic resonance (MR) imaging are likely to increase the detection of intramedullary metastases in living patients. $^{13,17,19,21,22)}$

Lung carcinoma is responsible for more than $50 \%$ of these metastases. The interval from the initial diagnosis of the primary tumor until the detection of metastasis is less than 2 years in most cases. ${ }^{5,10}$ ) Thyroid carcinomas except anaplastic type are gener-

Received August 31, 1995; Accepted February 13, 1996 ally considered less aggressive lesions with slow growth and protracted natural history. Although often accompanied by distant metastasis, only three intramedullary spinal cord metastases have been reported. ${ }^{2,11,24)}$

We present a patient with an asymptomatic brain metastasis from a thyroid carcinoma which had been resected 11 years previously.

\section{Case Report}

A 60-year-old male had undergone radical neck dissection for thyroid carcinoma 11 years previously. Radioactive iodine had been administered orally in three cycles over a 3-year period. He had been well until he felt dysesthesia and motor weakness of the bilateral lower extremities 2 months before admission. His symptoms advanced progressively. He presented at a local hospital, where myelography and postmyelography computed tomography (CT) revealed an intramedullary mass in the thoracic cord. He had paraparesis and hypesthesia below the level of the T-10 segment. His sphincter function was still preserved. On February 21, 1994 he was transferred 
to Kagawa Medical University Hospital.

Radiography of the spine and chest showed no abnormalities. Myelography and postmyelography CT revealed a localized swelling of the cord at the T- 8 level. MR imaging clearly disclosed an intramedullary lesion (Figs. 1 and 2) as an isointense mass and a small hyperintense area caudal to the mass on $\mathrm{T}_{1}$-weighted images, a hyperintense mass with a caudal hyperintense area on $T_{2}$-weighted images, and a markedly en-

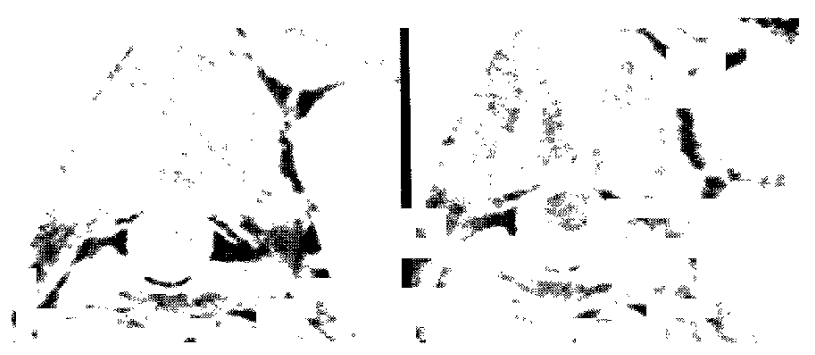

Fig. 1 Axial MR images at the T-8 level, showing an isointense tumor within the spinal cord on the $\mathrm{T}_{1}$-weighted image (left), enhanced after Gd-DTPA infusion (right). hanced mass with a dorsal linear enhancement with administration of gadolinium-diethylenetriaminepenta-acetic acid (Gd-DTPA). MR imaging for screening of intracranial pathology revealed a heterogeneously enhanced lesion accompanied by hemorrhage in the right cerebellar hemisphere (Fig. 3). Wholebody scans with thallium-201 chloride and technetium-99m hydroxymethylene diphosphonate disclosed no definite abnormal uptake. Cytological examination of the cerebrospinal fluid obtained at myelography disclosed no malignancy. Spinal angiography was not performed.

Within a few days of admission, he was unable to move either lower extremity or to void urine. An emergency laminectomy was carried out from T-7 through T-9. Enlargement of the cord at the T-8 level and an abnormal vascular network on the cord surface were noted. Echography revealed a hyperechoic mass occupying almost the entire cord beneath the vascular network. Myelotomy exposed a deep red hypervascular tumor. The vascular network was connected to the tumor by the main drainer, as seen on the MR images. The tumor, measuring $0.8 \times 0.7 \times$ $2.2 \mathrm{~cm}$, was totally removed. A small hematoma adja-

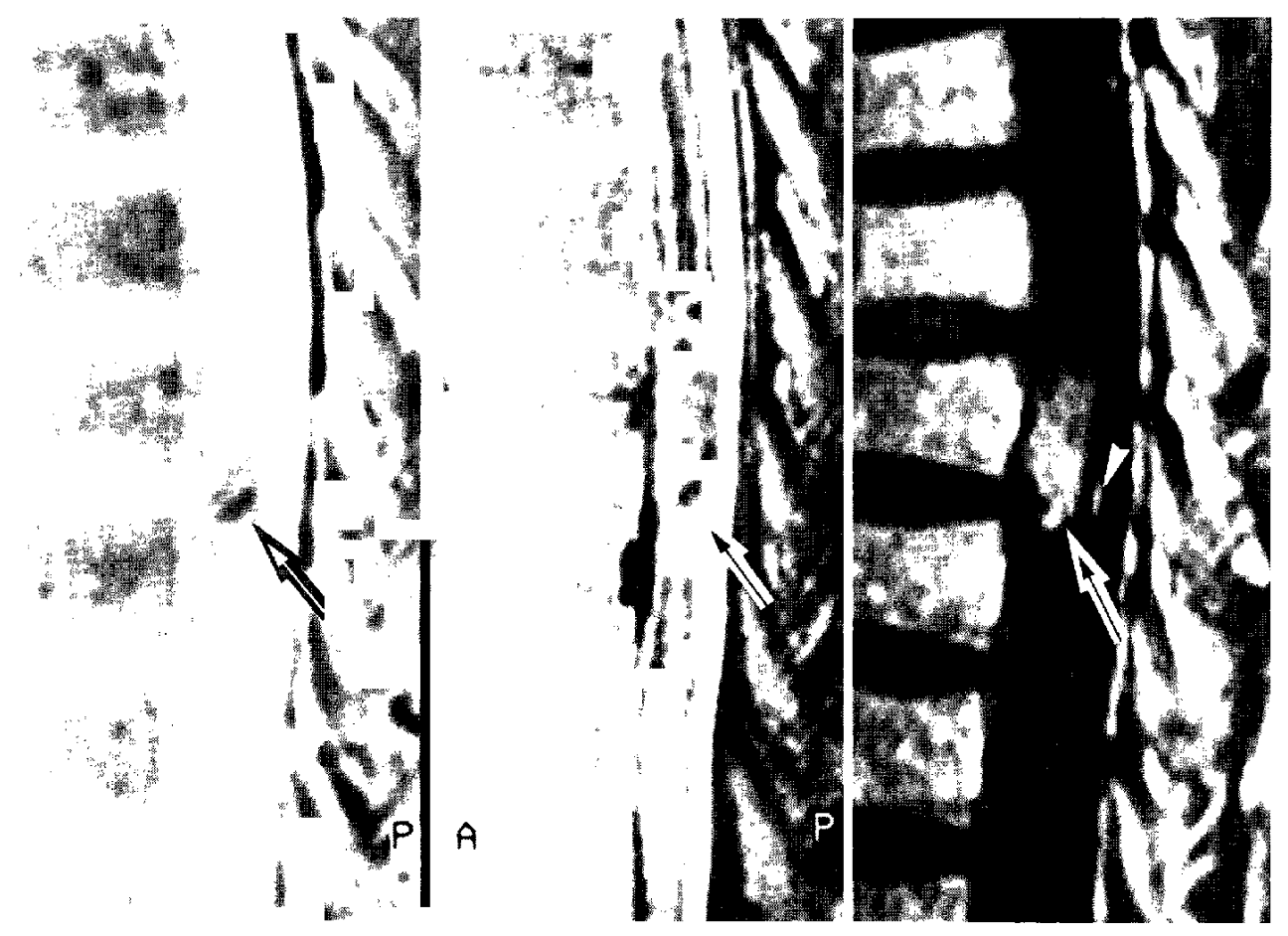

Fig. $2 \mathrm{~T}_{1}$-weighted (left), $\mathrm{T}_{2}$-weighted (center), and Gd-DTPA enhanced (right) MR images of the sagittal plane, showing the intramedullary tumor at the T-8 level. The hyperintense spot (arrows) caudal to the tumor and peritumoral hypointensity extending both rostrally and caudally may represent a small hematoma and hemosiderin deposits, respectively. The dorsal enhanced main drainer (arrowhead) is also seen. 

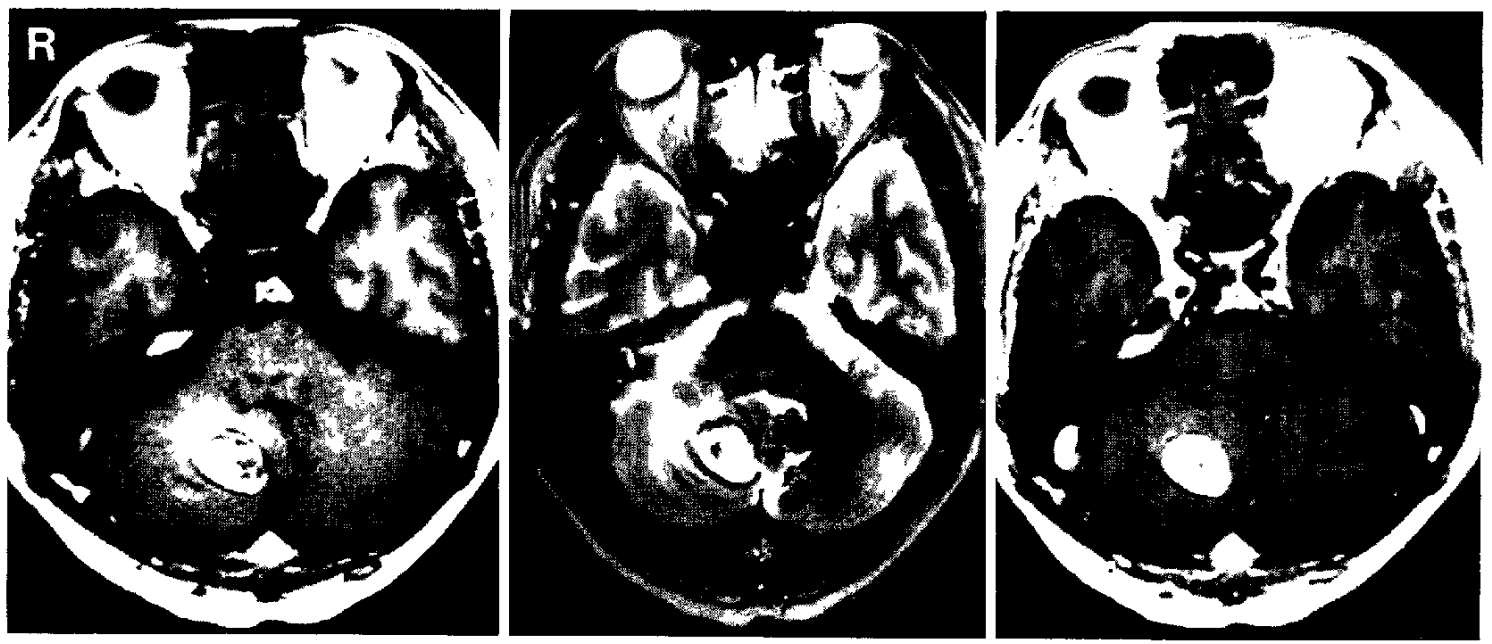

Fig. $3 \mathrm{~T}_{1}$-weighted (left), $\mathrm{T}_{2}$-weighted (center), and Gd-DTPA enhanced (right) MR images, disclosing a cerebellar metastasis with surrounding edema and intratumoral hemorrhage.

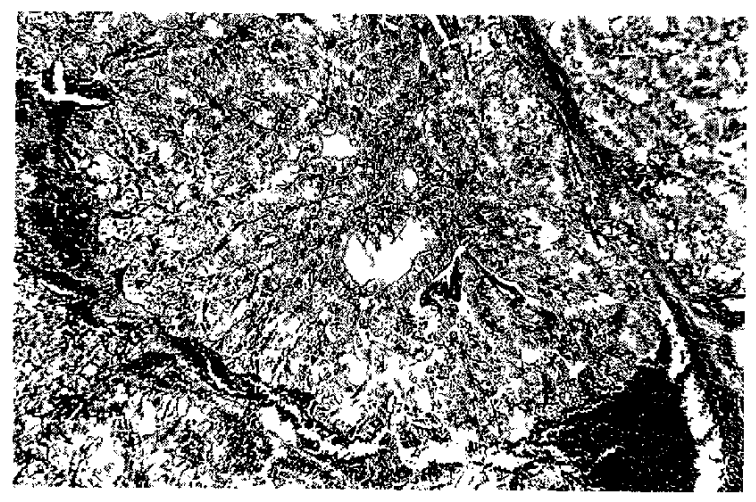

Fig. 4 Photomicrograph of the surgical specimen showing papillary adenocarcinoma, follicular variant type. Sporadic colloid formation is present among the tumor cells, which showed papillary arrangement with "ground glass" nuclei. No pleomorphism or mitosis is observed. HE stain, $\times 100$.

cent to the caudal pole, corresponding to the MR imaging findings, was evacuated. The surgical specimen was diagnosed as papillary adenocarcinoma, follicular variant type of the thyroid (Fig. 4).

Postoperatively, he could move both his legs, but the bladder dysfunction did not improve. Four weeks later, a deep red hemorrhagic tumor was resected from the right cerebellar hemisphere. The histology was quite similar to that of the cord lesion. External radiation was not carried out, because the tumor was assumed to be radioresistant. At present he can stand while holding a rail with both hands, and has been in good condition with stable deficits for the last 2 years.

\section{Discussion}

Differentiated thyroid carcinomas including papillary and follicular adenocarcinomas usually show features of reduced malignancy. The 10-year survival rate exceeds $50 \%{ }^{7,18}$ Several studies of the prognosis for thyroid carcinoma have indicated that most distant metastases occur within 5 years of initial diagnosis and the incidence is $6.6 \%$ to $23 \% .^{7,15)}$ However, it may develop even after 10 years. ${ }^{15,16,23)}$ The exceptionally long interval in the present case was probably related to the inactive features of the primary tumor. The most frequent metastatic sites are the lung and bone, ${ }^{15)}$ whereas metastasis to the central nervous system is less common. ${ }^{16}$ Extradural metastasis of thyroid carcinoma has occasionally been reported, ${ }^{8,9}$ but intramedullary metastasis is somehow extremely rare (Table 1)..$^{2,11,24)}$ Two of the reported cases were found at autopsy, and the third diagnosed only by myelography and surgically removed.

Intramedullary metastasis is difficult to differentiate from common extradural metastasis based on neurological findings, and there are no specific laboratory test indications including cytology of cerebrospinal fluid. Therefore, the diagnosis is based on the neuroimaging results. ${ }^{5,6,12)}$ Postmyelography $\mathrm{CT}$ and MR imaging are currently recognized as the modalities of choice for the detection of intramedullary tumors. ${ }^{17,21,22)} \mathrm{MR}$ imaging can disclose the loca- 
Table 1 Reported cases of intramedullary spinal cord metastasis of thyroid carcinoma

\begin{tabular}{|c|c|c|c|c|c|c|}
\hline Author (Year) & $\begin{array}{l}\text { Age/ } \\
\text { Sex }\end{array}$ & Histological type & $\begin{array}{l}\text { Level of } \\
\text { metastasis }\end{array}$ & $\begin{array}{l}\text { Extraspinal } \\
\text { metastases }\end{array}$ & $\begin{array}{c}\text { Confirma- } \\
\text { tion }\end{array}$ & Complications \\
\hline Chiari $(1905)^{2)}$ & $53 / \mathbf{F}$ & unknown & cervical & multiple & autopsy & none \\
\hline $\begin{array}{l}\text { Hashizume and Hirano } \\
(1983)^{11)}\end{array}$ & $76 / \mathrm{M}$ & undifferentiated* & $\mathrm{T} 11-12$ & brain & autopsy & $\begin{array}{c}\text { hemorrhage } \\
(\text { L1-2) }\end{array}$ \\
\hline$\underset{(1987)^{24)}}{\text { Winkelman }}$ et al. & $46 / \mathrm{M}$ & $\begin{array}{l}\text { follicular/ } \\
\text { papillary** }\end{array}$ & $\mathrm{C} 5-7$ & none & surgery & none \\
\hline Present case & $60 / \mathrm{M}$ & papillary*** & $\mathrm{T}-8$ & brain & surgery & $\begin{array}{c}\text { hemorrhage } \\
(\text { T8-9) }\end{array}$ \\
\hline
\end{tabular}

*Primary tumor not confirmed, ${ }^{* *}$ mixed type, ${ }^{* * *}$ follicular variant type.

tion and nature of the intramedullary tumor, and the tumor can be distinguished from surrounding edema with Gd-DTPA enhancement. ${ }^{13,19)}$ In the present case, the MR imaging findings of the location of the tumor, the draining vessel, and the hemorrhage adjacent to the caudal pole accorded well with the operative findings.

Spontaneous hemorrhage was presumably responsible for the acute progress of the myelopathy in our patient. Hashizume and Hirano ${ }^{11)}$ reported a case of intramedullary metastasis of presumed poorly differentiated thyroid carcinoma associated with a hemorrhage caudal to the tumor, identical to the configuration demonstrated in our patient. The cause of hemorrhage occurring rostral or caudal to metastatic tumor may be compression of the central artery. ${ }^{4,5)}$ Furthermore, metastasis of thyroid carcinoma often shows hemorrhagic features.

Radiotherapy and steroids are recommended for this type of pathology. ${ }^{5,6,12,22,24)}$ Surgical treatment other than biopsy is very seldom indicated. Surgery may be appropriate under the following conditions: a single encapsulated lesion and controlled systemic growth of a radioresistant tumor in a patient with a life expectancy of at least a few months. ${ }^{4,21,24)} \mathrm{We}$ would add the additional condition of progressive myelopathy. Our patient presented with a 2-month history of progressing myelopathy with no evidence of multi-organ dissemination except asymptomatic brain metastasis. We decided to treat our patient surgically because of the acutely escalating motor and sphincter disturbances.

Intramedullary metastases are very rarely curable because of the infiltrative and progressive features of the primary tumors. Regardless of the modality of treatment, satisfactory survival cannot be obtained in most patients. ${ }^{6,10}$ However, surgical removal should be considered for selected patients with slow-growing tumors such as thyroid carcinoma, especially when presenting with progressive com- pression myelopathy.

\section{References}

1) Chason JL, Walker FB, Landers JW: Metastatic carcinoma in the central nervous system and dorsal root ganglia. A prospective autopsy study. Cancer 16: 781-787, 1963

2) Chiari: IX. Verein deutscher Ärzte in Prag. Dtsch Med Wochenschr 35: 1416, 1905, cited in 20)

3) Costigan DA, Winkelman MD: Intramedullary spinal cord metastasis. A clinicopathological study of 13 cases. J Neurosurg 62: 227-233, 1985

4) Decker RE, Sundrani S, Citron ML, Herrschaft DS: Intramedullary spinal cord metastases treated by complete resection of tumor prior to radiotherapy and chemotherapy. Case report and review. Spine 12: 393-395, 1986

5) Dunne JW, Harper CG, Pamphlett R: Intramedullary spinal cord metastases. A clinical and pathological study of nine cases. QJM 61: 1003-1020, 1986

6) Edelson RN, Deck MDF, Posner JB: Intramedullary spinal cord metastases. Clinical and radiographic findings in nine cases. Neurology 22: 1222-1231, 1972

7) Franssila KO: Prognosis in thyroid carcinoma. Cancer 36: 1138-1146, 1975

8) Goldberg LD, Ditchek NT: Thyroid carcinoma with spinal cord compression. JAMA 245: 953-954, 1981

9) Goldstein SI, Kaufman D, Abati AD: Metastatic thyroid carcinoma presenting as distal spinal cord compression. Ann Otol Rhinol Laryngol 97: 393396, 1988

10) Grem JL, Burgess J, Trump DL: Clinical features and natural history of intramedullary spinal cord metastasis. Cancer 56: 2305-2314, 1985

11) Hashizume $Y$, Hirano A: Intramedullary spinal cord metastasis. Pathologic findings in five autopsy cases. Acta Neuropathol (Berl) 61: 214-218, 1983

12) Jellinger $K$, Kothbauer $P$, Sunder-Plassmann $E$, Weiss R: Intramedullary spinal cord metastases. $J$ Neurol 220: 31-41, 1979

13) Kamholtz R, Sze G: Current imaging in spinal metastatic disease. Semin Oncol 18: 158-169, 1991 
14) Meyer PC, Reah TG: Secondary neoplasms of the central nervous system and meninges. $B r J$ Cancer 7 : 438-448, 1953

15) Mizukami $Y$, Michigishi $T$, Nonomura A, Hashimoto T, Terahata S, Noguchi M, Hisada K, Matsubara F: Distant metastases in differentiated thyroid carcinomas. A clinical and pathologic study. Hum Pathol 21: $283-290,1990$

16) Nagamine $Y$, Suzuki J, Katakura R, Yoshimoto T, Matoba N, Takaya K: Skull metastasis of thyroid carcinoma. Study of 12 cases. $J$ Neurosurg 63: 526-531, 1985

17) Post MJD, Quencer RM, Green BA, Montalvo BM, Tobias JA, Sowers JJ, Levin IH: Intramedullary spinal cord metastases, mainly of nonneurogenic origin. AJNR Am $J$ Neuroradiol 8: 339-346, 1987

18) Russell MA, Gilbert EF, Jaeschke WF: Prognostic features of thyroid cancer. A long-term follow up of 68 cases. Cancer 36: 553-559, 1975

19) Sakuma S, Iwasaki $Y$, Isu T, Akino M, Sugimoto S, Takahashi A, Abe H, Inoue K: A case of intramedullary spinal cord metastasis from adenocarcinoma of corpus uteri. No Shinkei Geka 18: 653-657, 1990 (in Japanese)
20) Schwechheimer K, Lemminger JM: Intramedullary metastases: Report of 4 cases and review of the literature. Clin Neuropathol 4: 28-37, 1985

21) Thomas AW, Simon SR, Evans C: Intramedullary spinal cord metastases from epithelial ovarian carcinoma. Gynecol Oncol 44: 195-197, 1992

22) Tognetti F, Lanzino G, Calbucci F: Metastases of the spinal cord from remote neoplasms. Study of five cases. Surg Neurol 30: 220-227, 1988

23) Venkatesh S, Leavens ME, Samaan NA: Brain metastases in patients with well-differentiated thyroid carcinoma. Study of 11 cases. Eur J Surg Oncol 16: 448-450, 1990

24) Winkelman MD, Adelstein DJ, Karlins NL: Intramedullary spinal cord metastasis. Diagnostic and therapeutic considerations. Arch Neurol 44: 526-531, 1987

Address reprint requests to: Y. Honma, M.D., Department of Neurological Surgery, Kagawa Medical University, 1750-1 Ikenobe, Miki-cho, Kita-gun, Kagawa 761-07, Japan. 